open at the side at which the animal is swimming and so do not interfere with it, but closed on the other side to ensure that the water turns exactly with the wheel.

A parallel tube fitted with a photo-electric cell records the light intensity at a point beside where the animal is swimming. The experiments are performed with the wheel in a small glass greenhouse and the intensity of the light varied from bright daylight to complete darkness by a series of white, grey and black screens which can be drawn over the top.

Tracings from the recording drum of the swimming up and down of different animals under different conditions were shown and discussed. Calanus, a crustacean, almost the size of a grain of rice and the principal food of the herring, is shown to be able to climb $50 \mathrm{ft}$. in one hour, and another larger crustacean, Meganyctiphanes, almost an inch long, can climb as much as $305 \mathrm{ft}$. in the same time.

\section{APPLICATIONS OF PLASTICS}

$A^{\mathrm{T}}$

T the British Plastics Convention and Exhibition held in Olympia, London, during June 6-16, the plastics industry was given full opportunity for dis. playing its products and discussing the technical and practical aspects in the Convention Hall. The industry can claim considerable credit for the display. This relatively new and virile industry is one which uses its chemical raw materials in a careful and efficient manner to produce a very wide range of products and articles which are proving of much benefit to many industries to-day. They enable new assessments to be made of many old problems and processes; new values of durability, resistance to chemical attack or corrosion under atmospheric conditions, beauty and often lower-cost production resulting from their adoption. There is a large range of plastics materials available, and each one of the materials has itself an almost limitless range of applications best suited to its chemical and physical properties. There is in the lighter industries a very considerable scope for their adoption for very many uses.

The various plastics raw materials will be described first, and a few of their chemical and physical properties named. Then some of the outstanding applications for each plastic dealt with in the Exhibition and the Convention will be mentioned. Plastics materials are either moulded or otherwise fabricated into the many articles or other finished products used by the consumer, who may be the public, or the manufacturer of other products used in another industry. It should be stated here that the plastics materials referred to are the organic plastics only, but by common consent in the industry, rubber is excluded from the range.

Celluloid (or Nitrocellulose), discovered in 1865. This is the recognized pioneer material. It is thermoplastic, which means that after it has been shaped while it is hot, it is rigid when cold. But it will soften again on reheating and it can then be reshaped. Although it is the oldest plastic, it still has many uses which would not be improved upon by more modern materials, for example, table tennis balls, covering stretched over metals, such as automobile steering wheels and omnibus rails, hairbrush backs and tooth- brush handles, etc. Its inflammability, however, necessitates its use with caution. In its sheet or rod form it is remarkably tough, while, of course, it is unaffected to a large degree by water and many chemicals.

Cellulose Acetate, discovered in 1865. This noninflammable grade of plastic replaced celluloid for some uses where inflammability was feared. It is a thermoplastic. It came into prominence during the First World War as an aeroplane 'dope'. After that War ended, large stocks were available for utilization, when the process of converting the white powdered cellulose acetate into sheet and rod was developed. A new and relatively safe plastic was available for use in such things as lamp-shades, ornamental articles (for personal decoration, such as brooches, etc.), transparent sheet for packaging, astraldomes for aircraft, fountain-pen barrels, moulding powders, ete.

This material is extremely tough in all its forms and can be made in both rod and sheet form and as moulding material, clear, opaque or translucent (for example, tortoiseshell). Among numerous articles for consumer use made from cellulose acetate are fancy goods, door beading, drawer pulls and handles, spectacle frames, ciné non-flam film, packaging, showcards, protective eyeware.

Cellulose acetate is used to quite a large degree as the raw material for cellulose lacquers, extensively used for general decorative applied finishes. It is also used on ships' fittings, such as covering metal handrails, door furniture, etc.

Casein Plastics, first produced in 1885. This class of plastics is gradually giving way to more modern materials. It is available in sheet or rod form principally, and its present use is mainly for ornamental buttons for the garment industry, which articles are fabricated by machines from rod or sheet. It is not waterproof in the generally accepted sense of the word.

In addition to buttons, many fancy goods are made from it, such as barrels for pencils and fountainpens, and insulators and articles for resisting lowtension electric currents. Other applications are shoe buckles, knitting pins, umbrella handles, furniture handles, combs, etc., by machining from rod or sheet.

Phenolic Plastics, developed in 1907. This ty pe of plastics is the most extensively used range of materials at present. Phenolic plastics are thermosetting, which means that while hot they may be shaped; but during shaping a chemical reaction takes place which hardens the material in the mould. Further heating does not soften the moulding or shaped piece as in the case of thermoplastic materials. Thus, the finished articles or products made in phenolic plastics may be used for purposes where some resistance to heat is required. Phenolic plastics is only one type of thermosetting material, others being urea-formaldehyde and melamine-formaldehyde plastics (aminoplastics) as described later. The finished articles are extremely hard and, in addition to being resistant to heat, they are also resistant to a wide range of chemicals, but not to alkalis or strong oxidizing agents.

From the resins are made a wide range of products, such as moulding materials, paper and fabric laminated sheets, the more durable types of paints, and varnishes for electrical insulation, units of chemical plant as a structural material, acid-resisting floors, tanks, vats, pipework, etc. Large quantities are used for the manufacture of high-speed grinding wheels, brake and clutch linings for cars, adhesives for ply- 
wood manufacture, electric lamp capping cements, metal foundry core binders, etc.

Moulding powders are used to produce large television and radio cabinets in one piece, clock cases, rotary pump impellors, stud-welding pistol grips, car facia boards, Topham spinning boxes and spools for the rayon industry, vacuum cleaner bodies, shop counter drawers, ventilator fan cases and rotors and radio and electrical accessories. In addition, a large range of fancy goods such as cigarette caskets, desk calendars, etc., are produced. The present trend is for larger and larger mouldings to be made.

In its laminated form, using paper or fabric as the interlayer, phenolic plastic is used for plywood facing for furniture, wall panelling for ships and railway carriages, silent gear wheels to transmit both low and high powers, plating barrels, fish plates for railways, stern tubes for the propellor shafts of ships, roller bearings in steel rolling mills, aircraft propellors and structures (for example, the 'Mosquito'), moulded dinghy hulls, etc.

Amino-Plastics-Urea and Melamine, developed in 1920 and onuard. These are thermosetting. Mouldings with a high degree of beauty can be made, and thus they are used for fancy goods to a large extent. Urea resins are used for plywood adhesives, foundry sand.core binders, surface coatings, treatment of textiles to render them resistant to creasing, increasing the wet strength of papers, permanently stiffened finishes for textiles in admixture with starches or dextrins, controlling shrinkage of fabrics.

Urea and melamine resin mouldings are nontracking, and thus are widely used for certain electrical insulators where resistance to electrical surface leakage is essential.

Amino materials capable of being made in light colours and delicate pastel shades are used extensively for surface layers of laminated sheet for wall panelling and light-coloured materials for furniture finishing, for example, table and bar counter tops, etc.

Polyvinyl Plastics, developed during 1920-30. 'These are thermoplastics made as polyvinyl chloride or acet. ate or copolymers of chloride and acetate. They are also produced as the acetals, butyrals, etc. They are easily worked into sheets and are now extensively used for shower curtains, window furnishings, flooring tiles and raincoats (either as sheet or as coated fabric). They can be made with a high degree of decoration, either clear or opaque and with printed patterns. They are also used for upholstery (leathercloth), shoe uppers, ladies' handbags, transparent packaging, etc. In the chemical industry, polyvinyl chloride sheet (known as p.v.c.) is used for tank linings, protective clothing, filter cloths. Other applications are: safety glass for motor-car windscreens, yarns for weaving hosiery, fishing nets, etc., 'cocoon' casing for armaments in storage or being shipped to the East. Very large quantities are used for covering electrical cable instead of rubber, and for the manufacture of highly successful primers and other surface coatings.

Polyethylene Plastics, developed 1937-43. They are thermoplastic and possess a very high degree of both chemical and electrical resistance. They are wax-like to the feel and in appearance. They can be used for many items of chemical plant and utensils, such as pipes for conveying many chemicals, and for lining the interior of chemical tanks and vats, containers and utensils for hydrofluoric acid.

The evolution and use of polyethylene contributed substantially to the development of radar during the
Second World War, on account of its very low power factor.

It is extensively used as the interior core of undersea cables to reduce electrical losses. It is also used in transparent film form as a packaging material for foodstuffs, drugs (like 'Mepacrin' tablets), flexible bottles by the Plax extrusion blow technique, pharmaceutical tubes, cosmetic containers, etc. Balloons for high-altitude meteorological and other observations can be made of polyethylene. Tubing for cold-water plumbing is also made of polyethylene. Nylon, developed during 1928-38. This is a polyamide plastic and is a thermoplastic. It is best known for its use in hosiery and specialized garments. Indus. trial applications include tow ropes for gliders and gear wheels for impellor pumps. As a filler for phenolic moulding materials, it imparts great strength and resistance to alkalis and acids in mouldings. It is used extensively for surgical dressings where 'breathing' outwards only is required.

Methyl Methacrylate, developed in 1938. This is an ethenoid type of plastic and is thermoplastic. Some of its applications are for use in aircraft as radomes from transparent sheet, transparent models or housings for working parts for use in exhibitions, for example, motor-car engines, gear-box casings, ètc. It is also used for artificial teeth and dentures, some types of transparent mouldings, camera lenses, spectacle lenses, sculpture or highly ornamental carvings, and rods for transmitting artificial light round bends. It is a material of considerable beauty and consequently is used for a wide range of fancy goods for machining.

Polyethylene Glycol Terephthalate ('Terylene'), developed in 1939 and onwards. This is a true synthetic fibre, either silk-like or wool-like in properties. It can be made unshrinkable. It can be easily printed and is probably the most successful synthetic fibre for the textile industry to date. Its tenacity when wet is the same as when dry. It has good drape and handle, and has been used so far for lightweight suits. It is also used for filter cloth and laundry bags, ropes, cord, thread, corset cloth, brassière cloth, industrial overalls and sailcloth. It is expected to follow the pattern laid down by nylon.

The above is a brief outline of the state of the industry up to date; but new products are emerging rapidly and what is new to-day may be old to-morrow.

\section{H. V. РоттеR}

\section{LIBRARY SERVICE IN GREAT BRITAIN}

\section{ANNUAL CONFERENCE OF THE LIBRARY ASSOCIATION}

$S$ one of the means by which scientific and A technical knowledge is made more readily available to industry and to the community generally, the public library service must always be of some general interest to the man of science. While his own needs will be met in general by the libraries maintained by his professional institutions, or of the universities, research institutes or industrial organizations or firms with which he is associated, as well as by such national libraries as those of the Patent Office or the Science Museum, they are already to some extent served by the larger public libraries 